\title{
МЕРЫ ГОСУДАРСТВЕННОГО РЕГУЛИРОВАНИЯ ДЕЯТЕЛЬНОСТИ МАЛОГО И СРЕДНЕГО ПРЕДПРИНИМАТЕЛЬСТВА (МСП) В ЕС И РОССИИ (ЧАСТЬ 2) *
}

\author{
(c) 2019 Хотяшева Ольга Михайловна \\ кандидат экономических наук \\ доцент кафедры менеджмента, маркетинга и ВЭД имени И.Н. Герчиковой \\ научный руководитель магистратуры «Отраслевой маркетинг товаров и услуг» МГИМО \\ директор Бизнес-инкубатора МГИМО \\ директор Фонда развития инноваций и бизнес-инкубаторства МГИМО \\ Московский государственный институт международных отношений (университет) \\ Министерства иностранных дел Российской Федерации (МГИМО) \\ 119454, г. Москва, проспект Вернадского, 76 \\ (c) 2019 Слесарев Максим Александрович \\ преподаватель кафедры Менеджмента, маркетинга и ВЭД имени И.Н. Герчиковой \\ заместитель директора Бизнес-инкубатора \\ Московский государственный институт международных отношений (университет) \\ Министерства иностранных дел Российской Федерации (МГИМО) \\ 119454, г. Москва, проспект Вернадского, 76
}

После рассмотрения методов регулирования и поддержки МСП в ЕС имеет смысл обратиться к российским реалиям и проанализировать, какие аспекты могут быть полезны для нашего рынка. По данным ФНС России, по состоянию на 10 апреля 2018 г. в Российской Федерации зарегистрировано 6,1 млн. субъектов малого и среднего предпринимательства (из них 95\% микробизнес) [16], при этом их доля в валовом внутреннем продукте (ВВП) страны в 20152016 гг. находилась на уровне $20-21 \%$ и в последние годы не показывала ощутимого роста. По самым последним данным, озвученным 31 марта 2018 г. на заседании рабочей группы по разработке программы мер поддержки МСП Департамента развития малого и среднего предпринимательства и конкуренции Минэкономразвития России, в 2017 г. эта доля составила 22,3\%, или 18,8 трлн. руб. Указанный уровень является низким на фоне аналогичного показателя во многих зарубежных странах - более $50 \%$. Интересно, что плановый уровень этого показателя к 2024 г. также не достигает $50 \%$ и составляет всего $40 \%$ (42,9 трлн. руб.).

По данным с вышеупомянутого заседания, доля занятых в секторе МСП по результатам 2017 г. составила $26 \%$ общей численности занятого населения (19,3 млн. человек), что в сравнении с развитыми странами опять же является весьма низким показателям (там доля занятых в МСП колеблется от 35 до 80\%), при этом плановый уровень к 2024 г. составляет 34\%). На сектор МСП приходится порядка 5-6\% общего объема основных средств и всего 6-7\% общего объема инвестиций в основной капитал [7, с.17].

Структура МСП с точки зрения направлений экономической деятельности в 2016 г. выглядела следующим образом: 42,7\% малых и средних предприятий функционировали в сфере торговли, 18,3\% занимались операциями с недвижимым имуществом, арендой и предоставлением сопутствующих услуг, а почти $10 \%$ относились к сфере транспорта и связи.

Приведенные данные (в том числе и отраслевая структура МСП, имеющая большой «перевес» в сторону торговли и операций с недвижимым имуществом) свидетельствуют о том, что вклад сектора МСП в достижение приоритетных целей социально-экономического развития страны невелик. В текущих условиях малый бизнес не способен выступить в качестве мощного фактора структурной перестройки и модернизации российской экономики. Одной из причин, по мнению ряда исследователей, является то, что в государственной политике в отношении МСП по-прежнему наблюдается дефицит целеориентированности и системности, в связи с чем она мало коррелирует с основополагающими ориен-

\footnotetext{
* Продолжение статьи авторов, опубликованной в 12 номере журнала «Вопросы экономики и права» за 2018 год
} 
тирами развития экономики [7, с.18].

Лишь 4,7\% граждан России трудоспособного возраста являются начинающими предпринимателями [15], что является самым низким показателем среди стран-членов БРИКС: Бразилия 17,2\%, Китай - 15,5\%, ЮАР - 7\%, Индия - 6,6\%. В США доля граждан, начинающих собственный бизнес, в общей численности трудоспособного населения составляет 13,8\%.

О том, что государственная поддержка МСП на данный момент осуществляется в недостаточном размере, свидетельствуют данные Росстата, по которым мерами государственной помощи пользуются лишь 2,7\% хозяйствующих субъектов - представителей малого бизнеса: 2\% малых предприятий и 3,1\% индивидуальных предпринимателей. Вопреки этому годовые расходы Российской Федерации на поддержку МСП планомерно сокращались в период 2014-2017 гг. с 20 до 7,5 млрд. руб. Более того, о существовании программ поддержки малого и среднего бизнеса, в которой МСП безусловно нуждаются, особенно на начальном этапе своей деятельности, знают менее трети МСП (31,5\%) и лишь 28,9\% индивидуальных предпринимателей [13], что делает проблему слабой информированности бизнеса о господдержке и уровня доступности этой поддержки весьма актуальной.

По мнению ряда исследователей, о необходимости развития МСП в России говорится давно, однако предпринимавшиеся до сих пор меры не принесли ощутимого результата [14]. Данная проблема может быть решена в результате интеграции государственной политики в отношении МСП в практику стратегического планирования на базе комплексной системы правовых и институциональных новаций. Показательно, что после принятия Закона № 172-ФЗ «О стратегическом планировании в Российской Федерации» именно Стратегия развития МСП до 2030 года стала одним из первых документов, призванных реализовать качественно новый подход к государственному и муниципальному управлению.

В целом, на федеральном уровне инструментарий поддержки предпринимательства сводится к следующим пунктам:

(1) установление специальных налоговых режимов для субъектов МСП, в том числе упрощенной системы налогообложения;

(2) применение упрощенных способов ведения бухгалтерского учета и статистической отчетности (упрощенная финансовая отчет- ность и т.д.);

(3) установление особого порядка участия субъектов МСП в государственных и муниципальных закупках в качестве поставщиков и подрядчиков;

(4) введение моратория на плановые проверки органами государственного и муниципального контроля;

(5) финансовая поддержка кредитных организаций, которые, в свою очередь, увеличивают объемы банковского кредитования МСП на более выгодных условиях.

Важно отметить, что большую роль в стимулировании развития МСП играет также государственная финансовая поддержка - субсидии и субвенции,- которые, как правило, предоставляются на условиях софинансирования и не напрямую из федерального бюджета, а опосредованно, через региональные и местные бюджеты.

Одним из важных видов государственной поддержки МСП является поддержка в сфере налогообложения, которая состоит из 2-х компонентов: снижение налогового давления на предпринимательскую среду (налоговые льготы в рамках традиционной действующей налоговой системы) и упрощение системы учета и отчетности субъектов МСП по налогам. Основным (но далеко не единственным) документом, реализующим налоговую политику государства, являются Основные направления налоговой политики на очередной 2017 год и плановые 2018-2019 гг., и одним из главных пунктов этого документа является стимулирование деятельности МСП.

Положительные изменения коснулись и страховых взносов. В случае, если доходы от основного вида деятельности предприятия (страхователя) составляют не менее $70 \%$ от общей суммы доходов, то оно вправе применять пониженные (льготные) тарифы страховых взносов (20\%). Интересно, что право уплачивать страховые взносы по льготным тарифам необходимо подтвердить документально (например, копией налоговой декларации по УСН с отметкой налогового органа о принятии), в то время как право применения пониженных процентных ставок по УСН подтверждать налоговым органам не нужно, так как они не являются льготой (письмо Министерства финансов РФ от 21 октября 2013 г. № 03-11-11/43791).

В числе планируемых дополнительных мер стимулирования - предоставление налогопла- 
тельщикам, работающим по патентной системе налогообложения, возможности снижения стоимости патента на сумму страховых взносов, а также сокращение числа оснований для отказа в патентной системе (в том числе факт просрочки патентного платежа).

Немаловажным инструментом стимулирования деятельности МСП является предоставление преимуществ при государственных и муниципальных закупках. Согласно Федеральному закону «О контрактной системе в сфере закупок товаров, работ, услуг для обеспечения государственных и муниципальных нужд» от 05.04.2013 г. государственные и муниципальные заказчики обязаны осуществлять закупку товаров и услуг у субъектов малого предпринимательства в объеме не менее $15 \%$ от общего объема закупок (при условии соблюдения конкурентных способов закупки), и в перспективе этот показатель будет поэтапно повышаться. В течение 2018 г. планируется увеличение объема прямых закупок до $25 \%$.

Закон также предусматривает, что в случае, если исполнителем контракта являются субъекты малого предпринимательства, то в заключаемый между заказчиком и исполнителем контракт включается обязательное условие об оплате в сроки, не превышающие 30 дней с даты подписания документа о приемке. Важно добавить, что 1 мая 2017 г. Президентом РФ был подписан Федеральный закон от 01.05.2017 г. № 83-Ф3 «О внесении изменений в статьи 30 и 34 Федерального закона «О контрактной системе в сфере закупок товаров, работ, услуг для обеспечения государственных и муниципальных нужд», который изменил и расширил указанное требование: срок 30 дней теперь является стандартным для всех закупок, а в случаях, когда поставщиком выступает малое предприятие, он сокращается до 15 дней.

Несмотря на все позитивные сдвиги и преобразования в сфере госзакупок, можно выделить несколько проблемных зон, нуждающихся в изучении и принятии соответствующих мер:

(1) к поставщикам в рамках госзакупок нередко предъявляются необоснованно высокие требования, включающие, например, обязательное прохождение поставщиком сертификации в одобренной государственным заказчиком организации, при этом стоимость такой сертификации может доходить до 1,5 млн. руб., а сроки ее прохождения могут умышленно затягиваться в интересах других организаций;

(2) противоречивость действующего законодательства в сфере госзакупок приводит к тому, что в торгах можно выиграть путем использования банального ценового демпинга, что приводит к победе недобросовестных поставщиков и отражается на качестве поставляемых товаров, работ и услуг;

(3) даже в тех случаях, когда не реализуется сценарий пункта (2), зачастую контракты осуществляются иными организациями вместо «формальных победителей» по цене значительно ниже рыночной, что также сказывается на качестве и уровне ответственности исполнителей.

Одним из ключевых инструментов стимулирования деятельности МСП является расширение финансовой поддержки. С 2016 г. в данной области реализуются две основные программы развития: Национальная гарантийная система поддержки МСП (далее - НГС), в рамках которой субъектам МСП предоставляются поручительства и гарантии, и Программа стимулирования кредитования субъектов МСП.

По итогам 2015 г. доля кредитов с поддержкой НГС в общем объеме кредитной поддержки, оказанной МСП, составила $1,7 \%$, по итогам 2016 г. - 3\%, а по итогам 2017 г. - 3,1\%.

В 2017 г. был расширен лимит Программы стимулирования кредитования субъектов МСП до 175 млрд. руб. (реально в рамках данной программы было выдано кредитов на общую сумму 131 млрд. руб.) и в целях сопутствующего расширения кредитования банками субъектов МСП была запущена отдельная программа льготного кредитования - Программа 674, в которой приняли участие 3 кредитные организации: ПАО «Сбербанк», ПАО «Банк ВТБ» и АО «Россельхозбанк». В рамках Программы перечисленные банки получают субсидии из федерального бюджета на возмещение недополученных доходов по кредитам, выданным в 2017 г. субъектам МСП по льготной ставке (9,6\% годовых для средних предприятий и 10,6\% годовых для малых).

В 2018 г. программа льготного кредитования получила новый виток развития, и в соответствии с Постановлением Правительства РФ от 30.12.2017 г. в ней участвуют уже 15 российских кредитных организаций. Льготная стоимость кредитов обеспечивается за счет предоставления Банком России уполномоченным банкам кредитов под поручительство Федеральной корпорации развития малого и среднего предпри- 
нимательства под процентную ставку 6,5\%. Размер процентной ставки для субъектов в рамках «Программы 6,5» в свою очередь составляет 10\% годовых для средних предприятий и $11 \%$ годовых для малых. Срок льготного фондирования составляет до 3 лет (срок самого кредита может превышать этот срок), а размер кредита должен быть в диапазоне от 50 млн. до 1 млрд. руб. По состоянию на 1 марта 2018 г. с субъектами МСП по Программе заключено уже 165 кредитных соглашений на сумму 15,9 млрд. руб.

Вместе с тем нерешенные проблемы по-прежнему есть и по данному направлению. В частности, можно отметить очень высокий минимальный размер кредита, а также тот факт, что «Программа 6,5» открывает доступ к недорогим кредитным ресурсам лишь предприятиям в узких приоритетных секторах рынка: производственные отрасли, высокотехнологичные проекты, медицина [10, с. 7-12]. Однако, по мнению экспертов, проблема кроется уже в том, что стоимость фондирования не является главной проблемой МСП - основные сложности возникают в связи с неумением банков оценивать потенциальных заемщиков из сегмента МСП на основе неполной финансовой отчетности и при повышенных рисках, а также сложностями микропредпринимателей при формировании необходимого пакета документов для подачи заявки в банк. В этой связи многие субъекты МСП по-прежнему предпочитают обращаться за заемными средствами к частным инвесторам или в институты взаимного кредитования, где средства предоставляются по более высокой ставке, но с учетом специфики бизнеса, и как следствие уровень просрочки таких займов не превышает 5\% (в банках 15-17\%) [9, с. 90-95]. Нередко субъекты МСП финансируют свой бизнес за счет обычных кредитных карт и потребительских займов. Неудивительно, что, по данным Всемирного банка, доля банковского капитала в структуре инвестиций малого предпринимательства находится на уровне всего 6\%, а в целом Россия по объему кредитования малого бизнеса занимает 148-е место в мире.

Немаловажную роль в стимулировании деятельности МСП играет снижение административной нагрузки. Негативную роль играют и проверки со стороны различных контролирующих ведомств, и в настоящее время ведется активная работа по сокращению подобной административной нагрузки.
С 1 января 2016 г. по 31 декабря 2018 г. действует мораторий на плановые проверки в отношении юрлиц и ИП, отнесенных в соответствии со ст. 4 Ф3 «О развитии малого и среднего предпринимательства в Российской Федерации» от 24.07.2007 г. к субъектам малого предпринимательства. Кроме того, с 1 июля 2016 г. в ходе проверки представители органа госконтроля или муниципального контроля не вправе требовать от юрлиц и ИП представления документов (в том числе разрешительных) либо информации, находящихся в распоряжении иных государственных органов, органов местного самоуправления или подведомственных им органов, включенных в определенный Правительством РФ перечень.

Результатом перечисленных выше мер стало сокращение числа проверок. Так, по данным Минэкономразвития, если в 2015 г. было проведено всего 2,1 млн. проверок (0,9 млн. плановых и 1,2 млн. внеплановых), то в 2016 г. было проведено уже 1,7 млн. проверок (0,6 млн. плановых и 1,1 млн. внеплановых), то есть снижение составило от 15 до $30 \%$.

В 2016 г. в законодательство РФ об административных правонарушениях также были внесены изменения, в соответствии с которыми к субъектам МСП, впервые совершающим правонарушение, применяется предупреждение вместо административного штрафа. В результате этих изменений общее число решений о привлечении МСП к административной ответственности в первом полугодии 2017 г. снизилось на $17 \%$ по сравнению с первым полугодием 2016 г., а количество административных штрафов сократилось на 23,3\%.

В соответствии со Стратегией развития малого и среднего предпринимательства в Российской Федерации на период до 2030 г., количество субъектов МСП должно вырасти в 1,3 раза и достигнуть 7,7 млн., а доля банковских кредитов, выданных МСП, в общем объеме выданных банками кредитов, должна быть доведена до $23 \%$ [10, с. 7-12]. Чтобы обеспечить выполнение подобных планов, важно своевременно выявлять проблемы в законодательстве и вносить необходимые корректировки.

Анализ недостатков следует начать с акта, который остается одним из основных источников права в рассматриваемой области - Федерального закона «О развитии малого и среднего предпринимательства в Российской Федерации» 
от 24.07.2007 № 209-Ф3. Одним из существенных недостатков акта является универсальная схема структурирования субъектов МСП, что не отвечает реалиям развития предпринимательского сектора в современной экономике. Причем этот пробел носит настолько базовый характер, что приводит к некорректному и несбалансированному отнесению предприятий к микро-, малым и средним, а следовательно, в конечном счете искажает всю систему государственной поддержки, ссылающуюся на данную классификацию.

В частности, в сфере промышленности, транспорта, торговли и информационных технологий критерии определения размера предприятия не должны быть одинаковыми: если в первом и втором случае персонал в числе 100 человек указывает на действительно малое предприятие, то в предпоследнем и особенно последнем - на среднюю или даже весьма крупную компанию. Ту же отраслевую дифференциацию необходимо применять и к остальным критериям классификации, поскольку разные сферы бизнеса предполагают совершенно разные «весовые категории» по оборотам и нормам прибыли. Более того, некоторые исследователи считают целесообразной и межрегиональную дифференциацию критериев, поскольку условия и возможности развития МСП в различных регионах и крупных городах по всей России могут отличаться существенно, а значит, это является важным фактором при реализации политики государственной поддержки [7, с.19].

Большим пробелом в Законе можно считать также трактовку всех МСП как единого объекта государственной поддержки без сегментации по необходимым мерам поддержки. Например, Закон никак не учитывает те потребности, которые могут возникать у более зрелых МСП, делая избыточный акцент на поддержку начинающих предпринимателей («налоговые каникулы», мораторий на плановые проверки в первые годы деятельности и т.д.), в то время как увеличение доли именно долговременно функционирующих, зрелых МСП свидетельствует об их растущей выживаемости в российской экономике. Более того, именно для таких МСП характерен выход из теневого сектора, более высокая инвестиционная активность и привлекательность, расширение числа высокопроизводительных рабочих мест, производство более сложной продукции и т.д. Однако «перекос» государственной поддержки в сторону начинающего бизнеса делает невыгодным длительное развитие, и многие предприниматели предпочитают открывать создавать предприятия на короткий срок, периодически ликвидируя их и создавая новые.

Немаловажно отметить, что в Законе также нет четкого определения такого важного понятия с точки зрения стимулирования МСП, как «социальное предпринимательство», которое, несомненно, должно занимать особое место в системе предпринимательского права. Проблемы наблюдаются и в том, как Закон трактует поддержку инновационных МСП, что особенно важно для экономики, приоритетом развития которой является вектор на инновации. В условиях, когда инновационные МСП не получают никакой адресной поддержки (налоговое льготирование инновационных МСП, а также льготирование крупных предприятий, закупающих у МСП инновационные продукты), их доля в сфере технологических инноваций незначительна (5\% в 2015 г.) и не показывает признаков роста. Имеет смысл включить пункт и об обязательном квотировании инновационных предприятий в федеральных институтах развития (особых экономических зонах и др.).

Очевидно, что законодательству России в сфере регулирования предпринимательской деятельности не хватает детализации: оно дает слишком общую классификацию МСП и не учитывает меняющиеся потребности предприятий в зависимости от их возраста, статуса, инновационной активности, зачастую делая упор не на самых важных формах поддержки (например, налоговые преференции в первые годы деятельности, тогда как МСП именно этой стадии чаще всего работают «в тени» и не исполняют налоговые обязательства вообще). Перечисленные проблемы требуют более гибкой структуризации субъектов МСП по видам экономической деятельности. Существующие «базовые» критерии целесообразно дополнить специфическими критериями, ограничивающими круг субъектов, которые могут пользоваться теми или иными формами государственной поддержки. Таким образом, субъекты МСП в зависимости от специфики, характера и длительности деятельности могут рассчитывать на разные наборы мер поддержки и льгот, которые в большей степени адаптированы под их нужды.

Если резюмировать проблемы по различным формам государственной поддержки МСП и по- 
тенциальным способам их решения, то можно сформировать табл.4.

Общей и весьма существенной проблемой государственной политики в сфере поддержки МСП остается слабая информированность субъектов МСП о мерах государственной поддержки, что признают в самом Министерстве экономического развития РФ. Для решения данного вопроса в ведомстве планируют провести мониторинг качества Интернет-сайтов, информирующих о мерах господдержки МСП, а также реализовать федеральный телевизионный проект по популяризации предпринимательской деятельности [8, c.7].

В числе возможных способов решения перечисленных проблем, помимо упомянутых в табл. 4 , отдельного упоминания заслуживает развитие инфраструктуры поддержки МСП, которая по состоянию на конец 2017 г. насчитывает порядка 700 центров компетенций, оказывающих МСП комплексные услуги на различных стадиях развития бизнеса, в том числе и начальных. Подобные центры включают гарантийные и микрофинансовые организации, центры под- держки предпринимательства и центры инноваций социальной сферы, бизнес-инкубаторы и технопарки, центры поддержки экспорта, организации поддержки МСП в области инноваций и промышленного производства и т.п.

Несмотря на дополнительные расходы для региональных и местных бюджетов в связи с содержанием подобных организаций (их деятельность в большинстве случаев носит дотационный характер), они способны выполнять множество функций, которые обеспечивают максимально эффективное функционирование существующих правовых норм, в том числе путем информирования субъектов МСП о существующих программах поддержки, предоставления информационно-консультационных услуг, помощи в формировании заявок на льготные кредиты и участие в тендерах, предоставление площадей под офисы и производство на льготных условиях и др. Многообразие видов инфраструктуры поддержки и их специализация (на различных отраслях, на экспортно-ориентированных компаниях, на инновационных МСП) позволяет этим структурам формировать

Таблица 4. Недостатки законодательства РФ по различным формам поддержки МСП и возможные пути совершенствования

\begin{tabular}{|c|c|c|}
\hline Форма поддержки & Проблемы & Пути решения \\
\hline $\begin{array}{l}\text { Налоговые льготы и } \\
\text { преференции }\end{array}$ & $\begin{array}{l}\text { (1) Эффект от снижения ставок ниве- } \\
\text { лируется ростом иных сборов, в т.ч. } \\
\text { имущественных } \\
\text { (2) Ужесточение налогового админи- } \\
\text { стрирования } \\
\text { (3) Реализация льгот отдается на откуп } \\
\text { регионам }\end{array}$ & $\begin{array}{l}\text { (1) Разработка более гибкой системы } \\
\text { налоговых льгот, учитывающей статус и } \\
\text { специализацию предприятий, не дела- } \\
\text { ющей акцент на начинающих МСП } \\
\text { (2) Выравнивание правового дисба- } \\
\text { ланса между налоговыми органами и } \\
\text { налогоплательщиками } \\
\text { (3) Систематизация и уточнение пол- } \\
\text { номочий органов местного самоуправ- } \\
\text { ления }\end{array}$ \\
\hline $\begin{array}{l}\text { Государственные и му- } \\
\text { ниципальные закупки }\end{array}$ & $\begin{array}{l}\text { (1) Возможность манипуляции ходом и } \\
\text { результатами конкурса } \\
\text { (2) Несовершенства механизма осу- } \\
\text { ществления госзакупок, из-за которых } \\
\text { может страдать качество закупаемых } \\
\text { товаров, работ и услуг }\end{array}$ & $\begin{array}{l}\text { (1) Совершенствование критериев } \\
\text { оценки заявок } \\
\text { (2) Повышение анонимности торгов } \\
\text { путем перевода их на автоматизиро- } \\
\text { ванную электронную площадку }\end{array}$ \\
\hline $\begin{array}{l}\text { Программы льготного } \\
\text { кредитования }\end{array}$ & $\begin{array}{l}\text { (1) Кредиты на льготных условиях } \\
\text { доступны не для всех категорий МСП, } \\
\text { имеют завышенный минимальный по- } \\
\text { рог и не учитывают специфику бизнеса } \\
\text { (2) Сложности со стороны банков по } \\
\text { оценке заемщиков } \\
\text { (3) Сложности со стороны МСП в } \\
\text { оформлении заявок }\end{array}$ & $\begin{array}{l}\text { (1) Кастомизация льготных кредитных } \\
\text { продуктов под нужды различных кате- } \\
\text { горий МСП } \\
\text { (2) Развитие рынка венчурного инве- } \\
\text { стирования } \\
\text { (3) Расширение информационной и } \\
\text { консультационной поддержки для МСП } \\
\text { в вопросах льготного кредитования }\end{array}$ \\
\hline $\begin{array}{l}\text { Снижение администра- } \\
\text { тивной нагрузки }\end{array}$ & $\begin{array}{l}\text { (1) Полномочия органов надзора про- } \\
\text { должают расширяться } \\
\text { (2) Излишний акцент на начинающем } \\
\text { бизнесе }\end{array}$ & $\begin{array}{l}\text { Продолжение работы в области сокра- } \\
\text { щения числа обязательных требований, } \\
\text { выливающихся для МСП в существен- } \\
\text { ные дополнительные издержки }\end{array}$ \\
\hline
\end{tabular}

Источник. Составлено авторами. 
комплекс услуг с учетом потребностей целевых субъектов МСП. Дополнительным положительным эффектом для экономики является и то, что расширение инфраструктуры поддержки в целом способствует выходу из теневого сектора большего числа малых предприятий.

За 2016 г. количество объектов инфраструктуры выросло на $12 \%$. В соответствии с изменениями, внесенными в Федеральный закон № 209-Ф3, с июля 2016 г. к числу объектов инфраструктуры поддержки МСП были также отнесены многофункциональные центры предоставления государственных и муниципальных услуг (МФЦ).

В то же время наблюдается застой и даже деградация на рынке венчурного инвестирования, который, хоть и не имеет прямого отношения к инфраструктуре поддержки МСП, однако образует вместе с ней так называемую «инновационную систему», обладающую синергетическим эффектом (в нее входят и другие компоненты, например, ВУЗы). Венчурное инвестирование предполагает инвестирование в высокорисковые (как правило инновационные) проекты на ранних стадиях их развития и осуществляется специализированными венчурными фондами или частными венчурными инвесторами и бизнес-ангелами. Именно такой источник финансовых средств для МСП, как венчурный рынок, хоть и не предполагает существенных льгот, однако способен достаточно эффективно фильтровать потенциально успешные проекты и учитывать особенности и потребности финансируемых проектов.

К сожалению, на долю России приходится менее $1 \%$ общего объема венчурного инвестирования в мире, а создаваемые региональными властями организации инфраструктуры инвестиционной поддержки часто занимаются инвестициями в более предсказуемые, но и потенциально менее прибыльные проекты, тем самым нарушая принципы венчурного рынка. Специализированные же венчурные фонды, такие как Фонд содействия развитию венчурных инвестиций в малые предприятия научно-технической сферы г. Москвы, имеют тенденцию к сокращению объемов венчурных вложений (например, 63,4 млн. руб. в 2015 г. против 50,1 млн. руб. в 2016 г. у упомянутого Фонда). Учитывая, что развитый венчурный рынок - это жизненно важный для инновационных предприятий институт, данное обстоятельство безусловно требует внимания и участия со стороны законотворческих органов.

Таким образом, меры государственного регулирования и поддержки деятельности МСП в России по-прежнему характеризуются рядом серьезных недоработок, не позволяющих МСП, с одной стороны, получить ощутимый стимул к развитию, а с другой стороны - стать основной движущей силой инновационного развития экономики. В этой связи не стоит игнорировать уже существующий позитивный зарубежный опыт, прежде всего опыт стран ЕС. Несмотря на существующие очевидные различия в экономических реалиях и менталитете, развитие предпринимательства в целом базируются на единых принципах, которые необходимо положить в основу государственной политики и законотворчества в этой сфере.

\section{Библиографический список}

1. Taxation trends in the European Union - Data for the EU Member States/ European Commission.2014.

2. World Bank, Ease of Doing Business Index, 2016.

3. N. Elert et al., Institutional reform for Innovation and Entrepreneurship, SpringerBriefs in Eco-nomics, DOI $10.1007,2017$.

4. COMMUNICATION FROM THE COMMISSION TO THE EUROPEAN PARLIAMENT, THE COUNCIL, ECONOMIC AND SOCIAL COMMITTEE AND THE COMMITTEE OF THE RE-GIONS Review of the «Small Business Act» for Europe/* COM/2011/0078

5. Официальный сайт Европейской Комиссии https://ec.europa.eu/growth/smes/promoting-entrepreneurship_ en

6. Communication from the Commission to the Council, the European Parliament, the European Economic and Social Committee and the Committee of the Regions - "Think Small First" - A "Small Business Act" for Europe $\{$ SEC(2008) 2101\} \{SEC(2008) 2102\} \% COM/2008/0394 final

7. Бухвальд Е.М., Валентик О.Н. Стратегическое планирование и законодательство о развитии и поддержке малого и среднего предпринимательства. // Известия УрГЭУ. 2017. № 1(69).

8. Могилевская А. Малый бизнес не слышал о поддержке // Ежедневная деловая газета РБК. 05.07.2017 № 1162017. 
9. Паршина Е.Н. Проблемы и меры государственного регулирования малого и среднего предпринимательства в современной России // Наука и образование: хозяйство и экономика; предпринимательство; право и управление. - 2017. - № 10 .

10. Ручкина Г.Ф. Финансовая поддержка как ключевая составляющая в развитии субъектов малого и среднего предпринимательства. // Банковское право. 2017. № 5.

11. Светличный Г.В. Расширение возможностей для малых предприятий и ужесточение требований к заказчикам как основные акценты новаций в госзакупках // Вестник СевКавГТИ. 2017. Т. 1. № 3.

12. Шестакова Е.В. Проблемы развития российской налоговой системы в направлении гармонизации интересов государства и предпринимателей в сфере налогообложения // Налоги. 2016. № 4.

13. Сплошное наблюдение за деятельностью малого и среднего бизнеса за 2015 год. Электронный ресурс. Официальный сайт Росстат. http://www.gks.ru/free_doc/new_site/business/prom/splosh.html

14. Государственное регулирование предпринимательской деятельности: коллективная монография / под науч. ред. профессора В.С. Белых.- М.: Проспект, 2017.

15. Глобальный мониторинг предпринимательства 2014. https://www.gemconsortium.org

16. Единый реестр малого и среднего предпринимательства. https://ofd.nalog.ru 